\title{
CORRELATION OF SLEEP MACROSTRUCTURE PARAMETERS AND IDIOPATHIC EPILEPSIES
}

\author{
José Roberto Santiago Barreto', Regina Maria França Fernandes², \\ Américo Ceiki Sakamoto 3
}

\begin{abstract}
Sleep and epilepsy share some common mechanisms. The objective of the present investigation was to study the macrostructure of sleep in patients with idiopathic epilepsies, focal and generalized, comparing these two groups to each other and to a control group of 12 individuals without epilepsy. A total of 35 polysomnographies were performed, 12 of them in the control group, 10 in patients with idiopathic generalized epilepsies, and 13 in patients with idiopathic focal epilepsies. Antiepileptic medications were maintained for ethical reasons. The group with idiopathic focal epilepsy showed an increase in the total recording time $(p=$ 0.04 ) and the group with idiopathic generalized epilepsy had a reduction of phase 4 NREM sleep. The efficiency of total sleep period and of total sleep time was also lower in the group with idiopathic generalized epilepsy ( $p=0.03$ in both cases). We concluded that the group with idiopathic generalized epilepsy presents sleep of poorer quality, whereas the group with idiopathic focal epilepsy presents a tendency toward an excessive somnolence.
\end{abstract}

KEY WORDS: sleep, epilepsy, idiopathic epilepsy, polysomnography.

\begin{abstract}
Correlação entre parâmetros da macroestrutura do sono e epilepsias idiopáticas
RESUMO - Sono e epilepsia compartilham alguns mecanismos comuns. O objetivo deste estudo foi analisar a macroestrutura do sono em pacientes com epilepsias idiopáticas, comparando os grupos com epilepsias focais e generalizadas entre si, e ainda com um grupo controle sem epilepsia. Foram realizadas 35 polissonografias, 12 em indivíduos controle, 10 em pacientes com epilepsia generalizada idiopática (EGI) e 13 em pacientes com epilepsia focal idiopática (EFI). As drogas antiepilépticas foram mantidas por razões éticas. O grupo com EFI mostrou aumento do tempo total de registro, enquanto o grupo com EGI teve redução no sono não-REM fase 4. A eficiência do sono medida pelo período total de sono e pelo tempo total de sono foi menor no grupo com EGI. Concluímos que o grupo com EGI tem sono de pior qualidade e que o grupo com EFI apresenta tendência à sonolência excessiva.
\end{abstract}

PALAVRAS-CHAVE: sono, epilepsia, epilepsia idiopática, polissonografia.

The relationship between sleep and epilepsy has drawn great interest of physiologists and clinical neurophysiologists, specially because of some common mechanisms shared by the two conditions. Sleep is a physiological state during which vigilant consciousness is temporarily abolished and responses to environmental stimuli are decreased. It is cyclic and associated to various changes in multiple functions, such as behavior, endocrine and other functions ${ }^{1}$. The sleep/wakefulness cycle (SWC) is regulated by several mechanisms and some of them also affect the expression of epilepsy. These common mechanisms can possibly lead to modifications of the SWC in epileptic patients.
Idiopathic epilepsies usually affect patients with positive family history of epilepsy and no signs of structural lesion nor neurodevelopmental delay. They may manifest early in life and usually have a benign course. Idiopathic epilepsies can be sub-classified in two groups: idiopathic focal epilepsies (IFE) such as benign epilepsy with centrotemporal spikes (BECTS) and idiopathic generalized epilepsies (IGE) such as childhood absence, juvenile absence and juvenile myoclonic epilepsy. Epilepsy may cause changes in sleep architecture, the more common ones being increased latency to sleep, increased number and duration of arousals, reduction of sleep efficiency, presence of $\mathrm{K}$ complexes and abnormal or reduced

Department of Neurology, Psychiatry and Clinical Psychology of the Ribeirão Preto School of Medicine, University of São Paulo (USP), Ribeirão Preto SP, Brazil: ${ }^{1}$ Assistant Physician; ${ }^{2}$ Assistant Professor; ${ }^{3}$ Associate Professor. This study was supported by CNPq and FAEPA (Fundação de Apoio ao Ensino, Pesquisa e Assistência do Hospital das Clínicas da Faculdade de Medicina de Ribeirão Preto).

Received 10 Agusto 2001, received in final form 24 January 2002. Accepted 31 January 2002.

Dr. Américo C. Sakamoto - Hospital das Clínicas de Ribeirão Preto USP - Avenida dos Bandeirantes 3900 - 14048-900 Ribeirão Preto SP Brasil.E-mail: sakamoto@fmrp.usp.br 
sleep spindles, increased phase 1 NREM sleep, reduction of deep NREM sleep, fragmentation or reduction of REM sleep, and increased transitions between sleep stages ${ }^{2,3}$.

The objective of the present investigation was to study the macrostructure of sleep in patients with IGE and IFE, by comparing the two groups each other and to a control group. Effects of antiepileptic drugs (AEDs) in the results were also investigated.

\section{METHOD}

We analyzed 23 polysomnographies (PSG) of patients with idiopathic epilepsies followed up in the Epilepsy Outpatient Clinic of the Ribeirão Preto School of Medicine, University of São Paulo. Of the total, 13 patients had IFE, more specifically BECTS and 10 IGE, including childhood absence epilepsy ( 6 patients), juvenile absence epilepsy (3 patients), and juvenile myoclonic epilepsy (1 patient). The control group (CG) consisted of 12 normal children without epilepsy or other known diseases (subjects 1 to 12), 4 males and 8 females, ages ranging from 4 to 17 years old, mean of 10.8 years. The main characteristics of the two subgroups of epileptic patients are listed in Tables 1 and 2.

The PSGs were performed as a single-night recording, with the AEDs kept unchanged for ethical reasons. To evaluate the effects of medication in the results, we divided the two groups of epileptic patients in another two subgroups, with AEDs (16 patients) and without AEDs (7 patients). We further subdivided the BECTS group in other two subgroups: with AEDS (6 patients) and without AEDs (7 patients).

No patient presented epileptic seizures neither during the PSG nor during the preceding month, according to patients' and families' report. The exams were performed considering the habitual sleep time of the patients.

The following inclusion criteria were used: electroencephalogram (EEG) and clinical history consistent with idiopathic epilepsy, normal neuropsychomotor development, normal neurological examination, well controlled epileptic seizures, normal computerized tomography (when performed), and parental consent.

Nihon-Kohden (Neurofax) polygraphs were used. The recording was performed using a mechanical writing system at a habitual paper speed of $10 \mathrm{~mm}$ per second. Electrode placement and tracing analysis were according to recommendations by Rechtschaffen and Kales ${ }^{4}$.

All data were statistically analyzed through the chisquare test and for adherence of fit for all variables. When the distribution of the variable was normal we employed

Table 1. Characteristics of the IGE group.

\begin{tabular}{|c|c|c|c|c|c|c|c|c|c|c|c|}
\hline Patient & 13 & 14 & 15 & 16 & 17 & 18 & 19 & 20 & 21 & 22 & Mean \\
\hline Age (years) & 15 & 10 & 14 & 14 & 10 & 12 & 11 & 16 & 8 & 12 & 12.2 \\
\hline Sex & $\mathrm{F}$ & $\mathrm{F}$ & $\mathrm{F}$ & $\mathrm{F}$ & $\mathrm{F}$ & $\mathrm{F}$ & $M$ & M & M & M & \\
\hline Sz. time & Noct & Morn & Noct & Morn & Morn & Eve & Noct & Morn & Morn & Noct & \\
\hline Seizures & A & $A$ & $A$ & $A$ & A & $A+T C$ & $A+T C$ & $\mathrm{Mi}+\mathrm{A}+\mathrm{TC}$ & $A$ & $A$ & \\
\hline EEG & $\operatorname{SW}(4 / 5)$ & SW(5) & $\operatorname{sW}(3)$ & SW(3) & SW(3) & $\operatorname{sW}(3 / 4)$ & SW(3) & SW(3) & SW(3) & $\operatorname{SW}(3)$ & \\
\hline CT & NL & - & - & NL & - & NL & - & $\mathrm{NL}$ & - & - & \\
\hline Medication & $\mathrm{CLB}+\mathrm{ETS}$ & VPA & LAM & VPA & VPA & CLB & VPA & VPA & ETS & VPA & \\
\hline
\end{tabular}

F, female; M, male; Noct, nocturnal; Morn, morning; Eve, evening; A, absence; TC, tonic-clonic; Mi, myoclonic; SW, spike-wave (Hz); NL, normal; CLB, clobazan; ETS, etossuximide; LAM, lamotrigine; VPA, valproic acid; CT, computerized tomography; EEG, electroencephalogram.

Table 2. Characteristics of the IFE group.

\begin{tabular}{|c|c|c|c|c|c|c|c|c|c|c|c|c|c|c|}
\hline Patient & 23 & 24 & 25 & 26 & 27 & 28 & 29 & 30 & 31 & 32 & 33 & 34 & 35 & Mean \\
\hline Age (years) & 7 & 10 & 9 & 10 & 6 & 5 & 12 & 8 & 10 & 8 & 10 & 7 & 14 & 8.9 \\
\hline Sex & $\mathrm{F}$ & $\mathrm{F}$ & $\mathrm{F}$ & $\mathrm{F}$ & M & M & M & $\mathrm{F}$ & M & $\mathrm{F}$ & M & M & M & \\
\hline Sz. time & Noct & Morn & $\lg$ & Morn & $\lg$ & $\lg$ & $\lg$ & $\lg$ & Noct & Morn & Noct & $\lg$ & Noct & \\
\hline EEG & P4-PZ & T3 & $\mathrm{C} 3$ & CZ-PZ & CZ-PZ & $\mathrm{CZ}-\mathrm{C} 4$ & C3-P3 & C3-P3 & $\mathrm{C} 3$ & C3-C4 & C3-P4 & T4-T6 & $\mathrm{C} 4$ & \\
\hline$C T$ & NL & $\mathrm{NL}$ & - & $\mathrm{NL}$ & - & $\mathrm{NL}$ & - & - & NL & NL & - & - & - & \\
\hline Medication & CBZ & CBZ & FLU & CBZ & - & FB & - & - & - & - & CBZ & - & $\mathrm{CBZ}$ & \\
\hline
\end{tabular}

F, female; M, male; Ig, ignored; Noct, nocturnal; Morn, morning; Eve, evening; CZ, PZ, C3, C4, P3, P4, T3, T4, T6 , localizations of the 10-20 system; NL, normal; PB, phenobarbital; CBZ, carbamazepine; FLU, flunarizine CT, computerized tomography; EEG, electroencephalogram 
analysis of variance (ANOVA), and when not normal we employed the Kruskal-Wallis (KW) test. The level of significance was set at $p \leq 0.05$. When a significant difference between groups was observed, we also applied the Tukey test after ANOVA and the Duncan test after the KW test.

\section{RESULTS}

\section{Results in minutes (Table 3)}

The IFE group presented a significantly longer total recording time (TRT) when compared to the control group $(p=0.04)$ and a significantly longer total sleep time (TST) than the IGE group $(p=0.01)$. Total wakefulness time (TWT) lasted longer in the IGE group than in the IFE group $(p=0.03)$. With respect to sleep stages, $S 1$ was significantly longer $(p=0.01)$ and S2 significantly shorter $(p=0.01)$ in the IGE group than in the IFE group. S3 duration did not show any group differences and S4 lasted longer in the control group than in the IGE group $(p=0.03)$. Total NREM sleep was significantly longer in the IFE group than in the IGE group $(p=0.001)$, while no difference in REM sleep was observed between groups.

\section{Results as percentage of total} recording time (Table 4)

The efficiency of sleep was analyzed considering the total sleep period and the total sleep time in relation to TRT, and the CG and the IFE groups had significantly higher values when compared to the IGE group ( $p=0.03$ in both cases). TWT was signi- ficantly longer in the IGE group than in the IFE group $(p=0.02)$.

S1 percentage was greater $(p=0.008)$ and S2 percentage smaller $(p=0.05)$ in the IGE group than in the IFE group. Again, S3 did not show any group difference and S4 percentage was significantly greater in the control group than in the IGE group $(p=0.02)$.

Percentage of NREM sleep was smaller in the IGE group than in the other two groups $(p=0.0006)$, with no difference in percentage of REM sleep $(p=0.68)$.

\section{Results as percentage of total sleep time (Table 5)}

S1 was higher in the IGE group than in the IFE group $(p=0.008)$. There was no difference in $S 2$ or S3. S4 was significantly higher in the control group than in the IFE group $(p=0.05)$.

\section{Comparisons of the two epilepsy groups,} with and without AEDs

The epilepsy group with AEDs presented more TWT $(p=0.05)$, wake after sleep onset $(p=0.01)$, sleep latency $(p=0.05)$ and S1 $(p=0.03)$ than the group without AEDs.

\section{Comparisons of the two BECTS} subgroups, with and without AEDs

There were no differences between BECTS group with and without use of medications.

Table 3. Sleep macrostructure in minutes, per group.

\begin{tabular}{lcccc}
\hline Variables & CG (1) Mean (SD) & IGE (2) Mean (SD) & IFE (3)Mean (SD) & p \\
\hline TRT & $420.08(47.17)$ & $445.60(21.50)$ & $461.39(42.23)$ & $0.04^{*} 1<3$ \\
TSP & $412.17(48.89)$ & $406.95(60.32)$ & $450.00(44.61)$ & 0.09 \\
TST & $388.29(51.92)$ & $368.75(75.99)$ & $441.62(47.45)$ & $0.01^{*} 2<3$ \\
TAAS & $23.88(25.24)$ & $38.20(53.80)$ & $8.38(10.51)$ & 0.20 \\
TWT & $31.79(26.87)$ & $76.85(72.02)$ & $19.77(23.72)$ & $0.03^{*} 3<2$ \\
Sleep latency & $7.71(6.10)$ & $11.45(9.56)$ & $7.85(11.00)$ & 0.30 \\
REM latency & $101.04(47.62)$ & $127.85(89.37)$ & $115.46(45.96)$ & 0.71 \\
S1 & $8.79(8.09)$ & $16.25(13.20)$ & $4.08(3.35)$ & $0.01 * 3<2$ \\
S2 & $194.00(34.14)$ & $194.15(52.38)$ & $239.19(31.51)$ & $0.01 *(1=2)<3$ \\
S3 & $16.58(3.82)$ & $16.05(7.40)$ & $19.12(8.15)$ & 0.84 \\
S4 & $78.75(17.07)$ & $45.60(37.80)$ & $71.50(27.53)$ & $0.03 * 2<1$ \\
NREM & $298.13(29.61)$ & $272.05(37.53)$ & $333.89(41.82)$ & $0.001 * 2<3$ \\
REM & $90.17(33.83)$ & $96.70(44.67)$ & $107.73(23.36)$ & 0.44 \\
\hline
\end{tabular}

TRT, total recording time; TSP, total sleep period; TST, total sleep time; TAAS, time awake after sleeping; TWT, total wakefulness time; Sleep latency, latency of sleep phase 1; REM latency, latency of REM; S1, S2, S3 and S4, phases 1, 2, 3 and 4 NREM sleep; NREM, total NREM sleep time; REM, total REM sleep time. ${ }^{*} \mathrm{p}<0.05$ 


\section{DISCUSSION}

The IGE group showed a reduced efficiency of sleep and of phase 4 NREM sleep. Thus, the patients with IGE presented a reduction in the total amount and in the depth of sleep. These effects may be attributed to the epilepsy itself or to the use of antiepileptic medications. However, it could also indicate that patients with IGE, even when properly treated, could present poorer quality of sleep.

In studies of generalized epilepsy, Terzano et al.5,6 did not find any changes in sleep structure but comparison of their results with ours is difficult due to the fact that the groups are different. In one of their groups there was a predominance of tonicclonic seizures while in the other absence seizures predominated, however their patients were older and their seizures had started later in life ${ }^{6}$. Sato et al. ${ }^{7}$ studied 12 children with absence seizures taking antiepileptic medications, average of 12 years of age, and with a predominance of girls. Although this group is more similar to ours, it did not show alteration in sleep parameters. Our results are more similar to the alterations previously described by Janz ${ }^{8}$, who reported that patients with awakening epilepsy (generalized epilepsy) present a decrease in deep sleep. However, we did not find an increase in superficial sleep, as reported by these authors, but rather an increased wakefulness time ${ }^{6,7}$. There was no difference between the sleep of IFE group with and without AEDs.

The differences between the control group and the IFE group occurred only in absolute terms. TRT and phase 2 NREM sleep lasted longer in the control group but no change was observed in sleep efficiency, which continued to be high. These findings in recordings in which the usual sleeping time of the patients was respected may suggest that patients with IFE have a greater need for sleep than the control group. Palm et al. ${ }^{9}$ demonstrated that preadolescent patients with epilepsy who were not experi-

Table 4. Sleep macrostructure as percentage of total recording time.

\begin{tabular}{|c|c|c|c|c|}
\hline Variables & CG (1) Mean (SD) & IGE (2) Mean (SD) & IFE (3) Mean (SD) & $p$ \\
\hline TSP & $98.07(1.46)$ & $91.22(12.12)$ & $97.57(4.43)$ & $0.03 * 2<(1=3)$ \\
\hline TSL & $92.40(6.43)$ & $82.70(16.20)$ & $95.71(4.89)$ & $0.03 * 2<(1=3)$ \\
\hline TAAS & $5.67(5.92)$ & $8.56(11.92)$ & $1.87(2.39)$ & 0.16 \\
\hline TWT & $7.60(6.43)$ & $17.30(16.20)$ & $4.29(4.89)$ & $0.02 * 3<2$ \\
\hline S1 & $2.14(1.95)$ & $3.62(2.88)$ & $0.88(0.70)$ & $0.008 * 3<2$ \\
\hline S2 & $46.28(7.53)$ & $43.47(10.88)$ & $51.99(6.06)$ & $0.05^{*} 2<3$ \\
\hline S3 & $4.00(1.02)$ & $3.62(1.69)$ & $4.13(1.61)$ & 0.71 \\
\hline S4 & $18.96(4.64)$ & $10.36(8.77)$ & $15.32(5.55)$ & $0.02 * 2<1$ \\
\hline NREM & $71.37(7.21)$ & $61.03(7.67)$ & $72.32(5.28)$ & $0.0006^{*} 2<(1=3)$ \\
\hline REM & $21.03(6.27)$ & $21.67(9.82)$ & $23.39(4.62)$ & 0.68 \\
\hline
\end{tabular}

TSP, percentage of total sleep period; TST, percentage of total sleep time; TAAS, percentage of time awake after sleeping; TWT, percentage of total wakefulness time; S1, S2, S3 and S4, percentage of phases 1, 2, 3 and 4 NREM sleep; NREM, percentage of total NREM sleep time; REM, percentage of total REM sleep time. * $\mathrm{p} \leq 0.5$

Table 5. Macrostructure of sleep as percentage of total sleep time per group.

\begin{tabular}{|c|c|c|c|c|}
\hline Variables & CG (1) Mean (SD) & IGE (2) Mean (SD) & IFE (3) Mean (SD) & $p$ \\
\hline S1 & $2.36(2.16)$ & $4.79(3.93)$ & $0.93(0.73)$ & $0.008 * 3<2$ \\
\hline $\mathrm{S} 2$ & $50.11(7.39)$ & $53.25(12.67)$ & $54.33(5.69)$ & 0.35 \\
\hline S3 & $4.34(1.10)$ & $4.36(1.67)$ & $4.39(2.00)$ & 0.99 \\
\hline S4 & $20.48(4.60)$ & $12.68(10.99)$ & $15.87(5.50)$ & $0.05 * 2<1$ \\
\hline NREM & $77.29(6.22)$ & $75.08(8.22)$ & $75.63(4.54)$ & 0.69 \\
\hline REM & $22.71(7.40)$ & $24.92(8.22)$ & $24.39(4.48)$ & 0.69 \\
\hline
\end{tabular}

S1, S2, S3 and S4, phases 1, 2, 3 and 4 of NREM sleep; NREM, percentage of total NREM sleep; REM, percentage of total REM sleep time. ${ }^{*} p \leq 0.05$ 
encing seizures and had not been using antiepileptic medication for 6 months still presented excessive somnolence, as documented by objective evaluation using the multiple sleep latency test (TMLS). This excessive somnolence may have been associated with the cognitive losses and behavioral disorders observed in these patients. According to Levine et al. ${ }^{10}$, there may be a negative relationship between sleep efficiency and satiety, i.e., natural sleep presents a given latency, a given TAAS and a given efficiency. When the first two parameters are reduced and the third is increased, there may be signs of a greater necessity for sleep ${ }^{10-12}$. On this basis, patients with increased sleep efficiency present a reduction of sleep latency in the MSLT ${ }^{9}$. In our patient series, the IFE group presented a lower TAAS (8.38 minutes versus 23.88 minutes for the control group) and a higher sleep efficiency $(95.7 \%$ versus $92.4 \%$ for the control group) even though the difference was not significant, supporting the possibility that the IFE group may indeed present excessive somnolence.

We may perhaps speculate that IFE, in addition to being influenced by delta sleep activities, may also change these activities, thus increasing their need for sleep. These alterations may be simply qualitative and are not detectable by the methods currently used to evaluate sleep.

Terzano et al. ${ }^{13}$ and Dalla Bernardina and Beghini ${ }^{14}$ did not find changes in the sleep of their patients with BECTS. The only alteration found by BaldyMoulinier ${ }^{15}$ was an increased latency for REM sleep that we did not detect in our patients. Clemens and Olah ${ }^{16}$ also did not find changes in sleep architecture in their group of patients with BECTS but found an increase in wakefulness time after sleep. According to these investigators, this is a constant finding in focal epilepsies, but this was the only BECTS group in which these results were observed. In our group TAAS was normal and a tendency to the opposite finding was actually observed, i.e., excessive somnolence, as discussed above.

When different epilepsy groups were compared, several differences were detected. Whereas the IFE group slept for a longer time, with a greater quantity of NREM sleep, especially S2, the IGE group presented longer wakefulness and a longer S1 time, with lower sleep efficiency. No studies were found in the literature in which this type of comparison was made. In the present study, we observed that the two groups of epilepsy had different effects that may be attributed in part to the use of medications. How- ever, there seems to be a continuum between these epilepsies. The physiopathological changes may affect the SWC in a different manner, causing a tendency to somnolence in the IFE group and a tendency to insomnia in the IGE group. However, the epileptic patients with use of medications presented poorer sleep, with a greater TWT, wake after sleep onset, sleep latency and S1. This difference occurred because the IGE group with medications was bigger than the EFI group with medications.

The major conclusions reached in the present study were that IGE patients presented an increased wakefulness time and a reduction of the total amount of sleep, especially deep sleep, demonstrating that epileptic patients, even when properly treated, have poor quality of sleep, and that IFE patients presented an increased quantity of sleep and of sleep efficiency, a fact that may be clinically interpreted as an increased need for sleep in this group.

\section{REFERENCES}

1. Velluti RA. Fisiologia do sono. In Reimão R (ed), Sono: estudo abrangente. 2.Ed. São Paulo: Atheneu, 1996:1-19.

2. Montplaisir J, Laverdière M, Saint-Hilaire JM. Sleep and epilepsy. In Gotman, J, Ives JR, Gloor P (eds). Long-term monitoring in epilepsy. EEG Clin Neurophysiol 1985;37(Suppl):215-239.

3. Shouse MN, Martins DA Silva A, Sammaritano M. Circadian rhythm, sleep, and epilepsy. J Clin Neurophysiol 1996;13:32-50.

4. Rechtschaffen A, Kales A. (eds). A manual of standardized terminology and scoring system for sleep stages of human sleep. Los Angeles: Brain Information Service/Brain Research Institute, University of California at Los Angeles, 1968.

5. Terzano MG, Parrino L, Anelli s, Boselli m, Clemens B. Effects of generalized interictal EEG discharges on sleep stability: assessment by means of cyclic alternating pattern. Epilepsia 1992;33:317-326.

6. Terzano MG, Parrino L, Anelli S, Halasz P. Modulation of generalized spike-and-wave discharges during sleep by cyclic alternating pattern. Epilepsia 1989;30:772-781.

7. Sato S, Dreifuss FE, Penry JK. The effect of sleep on spike-wave discharges in absense seizures. Neurology 1973;23:1335-1345.

8. Janz D, Beck-Mannagetta G, Spröder B, Spröder J, Waltz S. Childhood absence epilepsy (pyknolepsy) and juvenile absence epilepsy: one or two syndromes? In Wolf P (ed). Epileptic seizures and syndromes. London: Libbey, 1994:115-126.

9. Palm L, Anderson H, Elmqvist D, Blennow G. Daytime sleep tendency before and after discontinuation of antiepileptic drugs in preadolescent children with epilepsy. Epilepsia 1992;33:687-691.

10. Levine B, Roehrs T, Zorick F, Roth T. Daytime sleepiness in young adults. Sleep 1988;11:39-46.

11. Harrison $Y$, Horne JA. Should we be taking more sleep? Sleep 1995;18:901-907.

12. Roehrs T, Timms V, Zwyghuizen-Doorenbos A, Buzenski R, Roth T. Polysomnographic performance and personality differences of sleep and alert normals. Sleep 1990;13:395-402.

13. Terzano MG, Parrino L, Spaggiari MC, Barusi R, Simeoni S. Discriminatory effect of cyclic alternant pattern in focal lesional and benign rolandic interictal spikes during sleep. Epilepsia 1991;32:616-628.

14. Dalla Bernardina B, Beghini g. Rolandic spikes in children with and without epilepsy (20 subjects polygraphically studied during sleep). Epilepsia 1976; 17:161-167.

15. Baldy-Moulinier M. Sleep organization in benign childhood partial epilepsies. Epilepsy Res 1992;6(Suppl 6):121-124.

16. Clemens B, Oláh R. Sleep studies in benign epilepsy of childhood with rolandic spikes: I. Sleep pathology. Epilepsia 1987;28:20-23 